\title{
Research on System Reform and Mechanism Innovation of the Integration of Urban and Rural Education in China
}

\section{Miantao Sun}

Research Institute of Educational Economics and Administration

Shenyang Normal University, Shenyang, Liaoning, China

\begin{abstract}
The research on system reform and mechanism innovation of the integration of urban and rural education in China is proposed for implementing National Medium - and Long-term Plan for Education Reform and Development (2012-2020) so as to eliminate the gap between urban and rural education and realize the common and fair development of them. It is the requirement for solving the theoretical and practical problems in research of system reform and mechanism innovation of the integration of urban and rural education. Based on the theoretical analysis and practical exploration, this paper proposes that education system and education mechanism are different in connotation and denotation, however, they are also related to each other in many aspects. Therefore, in the reform of the integration of urban and rural education, the reform of education system and education mechanism should be carried out respectively but simultaneously.
\end{abstract}

Keywords: the integration of urban and rural education; reform of education system; innovation of education mechanism

\section{Introduction}

This paper aims to discuss how to realize the integration of urban and rural education, eliminate the gap between urban education and rural education and realize the common and fair development of urban and rural education through the reform of educational system and the innovation of educational mechanism. This is the requirement for carrying out the National Medium - and Long-term Plan for Education Reform and Development (2012-2020) smoothly. The strategic target of educational development in this plan is "to realize universal education of a higher level, to form fair education benefits all citizens and to provide more abundant high quality education". The integration of urban and rural education is an important content and guarantee to realize these targets. Furthermore, it proposed the integration of urban and rural education in "development task" and "safeguard measure".

This thesis is also the requirement to solve the theoretical and practical problems in the research of the integration of urban and rural education. What is education system? What is education mechanism? What are the relationships between education system and education mechanism? There are only few researches on these problems. There are some notifications on these questions: firstly, the mix of education system and education mechanism; secondly, mistaking system reform and mechanism innovation as the entire reform of education system or reform of talents cultivation; thirdly, mistaking system reform and mechanism innovation as the reform of education system or educational management system. In order to change these notifications and provide scientific grounds for the system reform and mechanism innovation of the integration of urban and rural education, it is necessary to conduct a deep discussion into education system, education mechanism and their relationships.

2. The theoretical analysis of education system, education mechanism and their relationships

2.1. The contents of the reform of education system and the innovation of education mechanism are different

\subsubsection{Education system (tizhi)}

Education system (tizhi) is the combination of education institutions and education regulations. The education institutions include education implementing institutions and education management institutions. The former refers to all levels and kinds of schools; the latter 
refers to all levels and kinds of education administrative institutions and all levels and kinds of school management institutions. Education regulations refer to regulations to set up education institutions and keep it working. They regulate the duties and responsibilities of the education institutions and the staff. The combination of school education institutions and relevant regulations produces all levels and kinds of school education systems. The combination of education management institutions and relevant regulations produces education management systems. The combination of education administrative institutions and relevant regulations produces all levels and kinds of education administrative systems. The combination of school management institutions and relevant regulations produces all levels and kinds of school management systems. In education system, the relationships between education institutions and education regulations are that the former is the carrier of education system and the latter is the core of education system. The relationships between school education system and education management system are that the former is the premise of the component and operation of education system and the latter is the guarantee of the component and operation of education system. In education management system, the relationships between education administrative system and school management system are that the former is the microscope education management system and the latter is the microscope education management system. ${ }^{[1]}$

\subsubsection{Education mechanism}

Mechanism refers to the interrelations and the modes of operation of each part of a machine. Extending this definition into different fields will produce different mechanisms. The education mechanism refers to the interrelations and the modes of operation of each part of education phenomena. It includes 3 basic types and 9 sub-types: the first one is hierarchy mechanism, which includes macroscopic mechanism, medium-scopic mechanism and microscopic mechanism; the second one is form mechanism, which includes administration and plan form, guidance and service form and supervision and service form; the third one is function mechanism, which includes motivation mechanism, restriction mechanism and guarantee mechanism. ${ }^{[2]}$

From the definition of education system and education mechanism, we can conclude that the connotation of the reform of education system is the reform of education institutions and education regulations. The reform of regulations is the core. The denotation of the reform of education system is the reform of all levels and kinds of school education systems and all levels and kinds of education management systems, including all levels and kinds of education administration systems and all levels and kinds of school management systems. The connotation of the reform of education mechanism is the reform of the interrelations and the modes of operation of each part of education phenomena. Its denotation is the reform of the each part of education hierarchy mechanism, education form mechanism and education function mechanism. The contents of education system and education mechanism are different.

\subsection{The reform of education system and the innovation of education mechanism are interrelated $^{[3]}$}

\subsubsection{The generation and development of education system and education mechanism are interconnected}

According to the view of practice of Marxist philosophy, in education phenomena, the first phenomenon is education activity. The elements of education activity such as the subject and object of education activity, the process and method of education activity and so on are interacted and then generate the operation mechanism of education activity. In order to conduct education activity orderly, education institutions and education regulations need to be established, and then education system is generated. The process of the generation of education system is the process of the generation of education mechanism. After the generation of education system, it interconnects with education activity, and then education mechanism is generated. In the process of the conduction of education activity, the construction of education system and the operation of education mechanism, a certain idea is needed, and then the education idea is generated. After the generation of 
education idea, it interacts with education system and education activity, which generates the operation mechanism of the entire education phenomena. From the analysis we can conclude that education phenomena are the unity of education activity, education system, education mechanism and education ideas. In this unity, education activity and education system are two relative independent categories, while education mechanism and education idea integrate in the other categories. Education mechanism exists in education system, education idea and education activity, and is different from the others. Education idea exit in education activity, education system and education mechanism, and is different from the others. In education phenomena, education activity, education system, education mechanism and education idea are interrelated, while education mechanism and education idea not only interact with the others but also act as a bond or bridge in the entire education phenomena.

From the analysis of the categories of education phenomena, we can conclude that education system and education mechanism interconnect with each other closely. From the vies of the order of the generation of them, the interconnections between them reflect in: firstly, the generation of education mechanism is earlier than the generation of education system; secondly, the generation of education mechanism is later than the generation of education system; thirdly, the generation of them are at the same time.

The generation of education mechanism is earlier than the generation of education system, because the education mechanism is generated with the generation of education activity. The education activity generated firstly and the education mechanism connects each part of education activity together. This kind of education mechanism is called non-normative education mechanism. It is not related to education system, and not regulated by education institutions and education regulations.

The generation of education mechanism is later than the generation of education system, because after the generation of education activity, education system generated which constrains education activity. The way of the education activity decides the education system and the education system affects the education activity is the role of mechanism. This kind of education mechanism is called normative education mechanism. It is connected with education system and regulated by education institutions and education regulations.

The generations of education mechanism and education system are at the same time, because when education system generates, education institutions and education regulations are interrelated and interconnected. The education sub-systems are interrelated with each other as well, which generates the operation mechanism of education system. This kind of education mechanism is called relative stable education mechanism. The education system and the education mechanism are simultaneous. As long as the education system is stable, the education mechanism won't change.

\subsubsection{Education system and education mechanism are mutually integrated in structure}

The structures of education system and education mechanism can integrate into each other. The structure of education system consists of education institutions, education regulations and all levels and kinds of school education system and education management system. In this structure, there exists an operation manner that connects all levels and kinds of education institutions, education regulations, school education system and education management system. The structure of education system exits in education mechanism. Because that the structure of education mechanism reflects the relationships among each part of education system. Education system and education mechanism can not be aparted in structure.

\subsubsection{Education system and education mechanism are complementary in property and function}

In education phenomena, for education system, it only regulates the scope, property and requirements of education activity indirectly through a manner, and this manner is the role of education mechanism. For education mechanism, it plays the role into education activity through a certain manner, i.e. by the means of the scope and requirements of education system. For example, the education activity in America is conducted in education system. The education system affects 
education activity indirectly by the means of guidance and service. Therefore, the education activity in microscope of government is in the trend of decentralization; in microscope of school is in the center of children in teaching. The manner of guidance and service works under education system.

\subsubsection{Education mechanism contains education system in scope}

The relationships and operation manner of education system with the other education phenomena are included in education mechanism. The relationships and operation manner of education activity, education system, education mechanism and education idea are a kind of education mechanism. It bonds these four categories together. Therefore, education system is an element of education mechanism, which contains education system.

\section{The practical exploration of system reform and mechanism innovation of the integration of urban and rural education in China}

\subsection{From the difference of education system and education mechanism}

In the integration of urban and rural education, the reform of education system and the innovation of education mechanism have their respective connotation and denotation of reform, and can not be mixed.

\subsubsection{The reform of education system of the integration of urban and rural education}

\subsubsection{The reform of the two elements of education system}

Firstly, the reform of education institutions includes the reform of school education institutions and the reform of education management institutions. The former is to arrange a reasonable layout of schools in urban and rural areas; the latter is to change the separation of education management institutions in urban and rural areas and establish education management institutions which can balance the reform and development of the integration of urban and rural education.
Secondly, there are many education regulations about the integration of city and countries. The main reforms currently are finance investment, use system, teacher's communication system and students' enrollment management system. The purpose is to make them to be good for the integration of urban and rural education.

Thirdly, education institution is the carrier of education system, while education regulation is the core of education system. Therefore, the reform of them should be conducted together.

\subsubsection{The reform of education sub-systems of the integration of urban and rural education}

Firstly, to build all levels and kinds of school education system of the integration of urban and rural education. All levels and kinds of schools in urban and rural areas should be uniformed in property and hierarchy. The uniform in property refers to that the general schools and vocational and technology schools should be uniformed in quantity and quality. So it is necessary to change the phenomena that rural areas stress on vocational and technology schools and urban areas stress on general schools. The uniform in hierarchy refers to that the pre-school education, primary education and secondary education should be uniformed in quantity and quality. So it is necessary to avoid the concentration of resources in city.

Secondly, to build all levels and kinds of education management system of the integration of urban and rural education, which include all levels and kinds of education administration system and school management system. The education administration system and the school management system have to be uniformed in institution setup, staff management, regulation arrangement and work content and manner.

Thirdly, to deal with the relationships between the reform of school education system and the reform of education management system, among all levels and kinds of school education system and education management system, and among all levels and kinds of education administration system and school management system. All these reforms should be carried out simultaneously. 


\subsubsection{The reform of education mechanism of the integration of urban and rural education}

Firstly, the reform of education hierarchy mechanism. It should give priority to the reform of macro mechanism, and then to the reform of medium and micro mechanism. Because of that only by balancing the reform and development of urban and rural education through macro adjustment and control, and motivating the activity of all facets in medium and micro mechanism can realize the integration of urban and rural education.

Secondly, the reform of education form mechanism. It should give priority to the mechanism of administration and plan, and then the mechanism of guidance and service. Because of that the manner of administration and plan can allocate all kinds of resources effectively, and the manner of guidance and service can coordinate the allocation of the resources better.

Thirdly, the reform of education function mechanism. The motivation mechanism can motivate the activity of all aspects; the guarantee mechanism can provide all kinds of supports; the restriction mechanism can balance the development of urban and rural education.

\subsection{From the relevance of education system and education mechanism}

In the reform of the integration of urban and rural education, the relevance of education system and education mechanism requires that to conduct the reform simultaneously, and the reform of them should adapt to each other.

Firstly, from the relevance of the generation of education system and education mechanism. When the generation of education mechanism is earlier than the generation of education system, the reform of education system and the innovation of education mechanism in the integration of urban and rural education should focus on the reform of education system. Because of that the education mechanism is new, and it needs a new education system to adapt to it and protect it. When the generation of education mechanism is later than the generation of education system, on the one hand, the innovation of education mechanism should be focused on. This way can promote the innovation of reform and system; on the other hand, the reform of education system should be focused on. The reform of education system can promote the change of education mechanism. When the generations of education system and education mechanism are at the same time, the relationship between the reform of education system and the innovation of education mechanism should be coordinated so as to make the generation and operation of education mechanism match the characteristics of education system, vice versa. The reform of them should be coordinated.

Secondly, from the mutual integration of education system and education mechanism. When conducting the reform of education system in the integration of urban and rural education, it is required to take the reform of education system as the innovation of education mechanism and to reform education system in the process of the innovation of education mechanism. It is required to think about how to design a scientific and reasonable manner which can connect all kinds of education institutions and education regulations and all levels and kinds of school education system and education management system, including all levels and kinds of education administration system and school management system. In this way, the education system produced in the process of the innovation of education mechanism can make the reform of education system and the innovation of education mechanism simultaneously.

Thirdly, from the complementary property and function of education system and education mechanism. In the reform of the integration of education system and education mechanism, when building an education system, it is required to build an education mechanism which is compatible with the education system so as to bring its role into full play; when building an education mechanism, it is required to build an education system which is compatible with the education mechanism so as to bring its role into full play under a certain institutions and regulations.

Fourthly, from the property of that education mechanism contains education system. In education reform of the integration of urban and rural education, except for the reform of education system and the innovation of education mechanism, the reform of education activity, education system, education idea and the innovation of education mechanism are needed. 


\section{References}

[1] Miantao Sun, "The New Annotation on Theory of Education Tizhi (System)", Educational Research, vol.12, 2004.

[2] Miantao Sun and Cuiping Kang, "The New Annotation on Theory of Education Mechanism", Educational Research, vol.12, 2006.

[3] Miantao Sun and Cuiping Kang, "The Exploration on Relationship between Reform of Education Tizhi (System) and Innovation of Education Mechanism", Educational Research, vol.7, 2010. 